\title{
Influence of chronic, low-level hydrodynamic forces on subtidal community structure
}

\author{
Christopher E. Siddon ${ }^{1,2, *}$, Jon D. Witman ${ }^{1}$ \\ ${ }^{1}$ Department of Ecology and Evolutionary Biology, Brown University, Providence, Rhode Island 02912, USA \\ ${ }^{2}$ Present address: JCSFOS, University of Alaska-Fairbanks Juneau, Alaska 99801, USA
}

\begin{abstract}
We combined a theoretical and experimental approach to examine the importance of hydrodynamic forces in causing a striking pattern of subtidal zonation between wave-exposed and protected sides of Halfway Rock, an island in the Gulf of Maine, USA. On the exposed side, prey species (kelp Alaria esculenta and blue mussels Mytilus edulis) dominated space at shallow depths (1 to $3 \mathrm{~m}$ ), while their consumers (sea urchins Strongylocentrotus droebachiensis and seastars Asterias forbesi) were restricted to depths $>3 \mathrm{~m}$. In contrast, these consumers foraged up to mean low water on the protected side. We hypothesized that the zonation pattern was caused by higher dislodgment of consumers at the shallow exposed (high-flow) site. Maximum calculated drag and lift forces on consumers ranged from 0.63 to 6.26 newtons $(\mathrm{N})$ at water velocities of $2.0 \mathrm{~m} \mathrm{~s}^{-1}$ and were an order of magnitude lower than their attachment strengths. Contrary to our hypothesis, these forces predicted $<6.0 \%$ dislodgment. In addition, transplant experiments indicated that significantly more urchins and seastars remained at the shallow exposed site than at the lower water-flow sites, where they attached, then quickly moved out of the area. In this system, water flow inhibited the movement of consumer species at lower velocities than was required to dislodge them, increasing the size of the hydrodynamically generated refuge for prey (kelp, mussels). Our study documents the importance of environmental indirect effects on the behavior of 2 ecologically important consumer species, and highlights the importance of chronic, low-level forces in structuring marine benthic communities.
\end{abstract}

KEY WORDS: Hydrodynamics $\cdot$ Drag $\cdot$ Dislodgment $\cdot$ Refuge $\cdot$ Community structure $\cdot$ Zonation $\cdot$ Sea urchin $\cdot$ Seastar

Resale or republication not permitted without written consent of the publisher

\section{INTRODUCTION}

Physical forces are widely recognized as influencing the size, shape and distribution of many species in terrestrial and marine ecosystems (Denny et al. 1985, Denny 1994). For example, wind modifies the size and shape of trees (Ennos 1997) and can also play a major role in shaping patterns of species distribution and abundance (Boose et al. 1994). Similarly, hydrodynamic forces (i.e. lift, drag, and acceleration) in wave-swept and tidal environments modify the morphology and distribution of organisms generated by either routine (Palumbi 1986, Blanchette 1997, Trussell 1997a), or catastrophic conditions (Denny 1988, Edmunds \& Witman 1991, Trussell 1997b). Generally, as wave-generated forces increase, body sizes decrease and relative attachment strengths increase (Gaylord et al. 1994, Denny 1999). Hydrodynamic forces generated by waves are one of the most important mechanisms of disturbance in coastal systems (Dayton 1971, Paine \& Levin 1981, Witman 1987). Extreme hydrodynamic forces exceed the mechanical limits of most or all organisms in the community, and thus provide a mechanism for ecological succession in disturbance-generated patches (Sousa 2001). Most of the previous studies of hydrodynamic disturbance, however, have concentrated on sessile species. Mobile species face many of the same hydrodynamic challenges, yet they have received comparatively less attention (Sousa 2001; but see Kawamata 1998, Duggins et al. 2001, Robles et al. 2001). 
Theory predicts that mobile consumers will be less tolerant to environmental stress, such as large hydrodynamic forces, than sessile species at the base of food webs (Menge \& Sutherland 1987). Hydrodynamic forces may therefore create a spatial 'non-coexistence' refuge (Menge \& Lubchenco 1981) for the more physically tolerant prey species, where they can persist in areas where predators cannot forage effectively. Recent studies have shown the importance of the interaction between hydrodynamic forces and predation on community structure (Leonard et al. 1998, Duggins et al. 2001, Robles et al. 2001). However, the mechanisms that govern this interaction vary considerably. For example, Duggins et al. (2001) demonstrated that while the movement and foraging effectiveness of the snail Lacuna vincta decreases as flow increases, their impact on the prey species Nereocystis leutkeana was highest at intermediate flows. These results suggest that the size of the prey refuge does not necessarily increase with increasing physical stress. Similarly, high flow may not always create a complete refuge from predators. Highly mobile species with short preyhandling times can reduce the effectiveness of the hydrodynamically generated prey refuge by maximizing consumption during periods of relatively low flow (e.g. during high tides; Robles 2001). To explain such variation in the effects of water flow on predation, Witman \& Dayton (2001) suggested that the impact of consumers is proportional to consumer mobility and the return time (1/frequency) of physically stressful conditions. This idea has yet to be explicitly tested.

In this paper, we examine the role of hydrodynamic forces in producing a striking zonation pattern in the shallow subtidal community in the Gulf of Maine. Specifically we examined the ability of the sea urchin Strongylocentrotus droebachiensis and the seastar Asterias forbesi to forage effectively at shallow depths. These species are well known for their ability to modify benthic community structure (Menge 1979, Himmelman et al. 1983, Witman 1987, Scheibling et al. 1999, Witman et al. 2003) and control the lower depth limits of kelp (Witman 1985, 1987) and mussels (Briscoe \& Sebens 1988). Here, we predict that their ability to maintain top-down (i.e. predatory) control of the community will decrease as hydrodynamic forces increase. We utilize a combined theoretical and experimental approach to examine the importance of drag and lift forces in maintaining the differential distribution of sea urchins and seastars. Specifically, we tested the hypotheses that (1) the scarcity of sea urchins and seastars at shallow exposed areas is maintained by dislodgment; or (2) the hydrodynamic forces inhibit sea urchin and seastar movement in these areas. Our data suggest that the difference in patterns of subtidal zonation between exposed and protected sides of the island is created by the inhibition of movement at flow velocities 5 to 10 times lower than those required to dislodge them.

\section{MATERIALS AND METHODS}

Study site. All data collection and experiments were conducted at 2 sites at Halfway Rock located $4.6 \mathrm{~km}$ off the coast of Marblehead, MA, USA $\left(42^{\circ} 30.158^{\prime} \mathrm{N}\right.$, $070^{\circ} 46.490^{\prime} \mathrm{W}_{\text {; Fig. }}$ ). One site (exposed) was oriented into the prevailing ocean swell while the other site (protected) was oriented northwest toward the mainland. Differences between sites were characterized by examining their community structure and hydrodynamic forces along a depth gradient.

Community structure. The abundance of the dominant organisms at both sites was quantified using a stratified random sampling design with depths corresponding to strata in October 1997 and November 2000. Photographs of randomly spaced $0.25 \mathrm{~m}^{2}$ quadrats were taken along horizontal transects at 6 depths ranging from 1 to $13 \mathrm{~m}$ (n ranged from 10 to 23 quadrats per transect). The photographic system consisted of a Nikonos V camera with a $15 \mathrm{~mm}$ lens and 2 strobes fitted to a rigid frame mounted above a $0.25 \mathrm{~m}^{2}$ quadrat (Witman 1985). To determine species

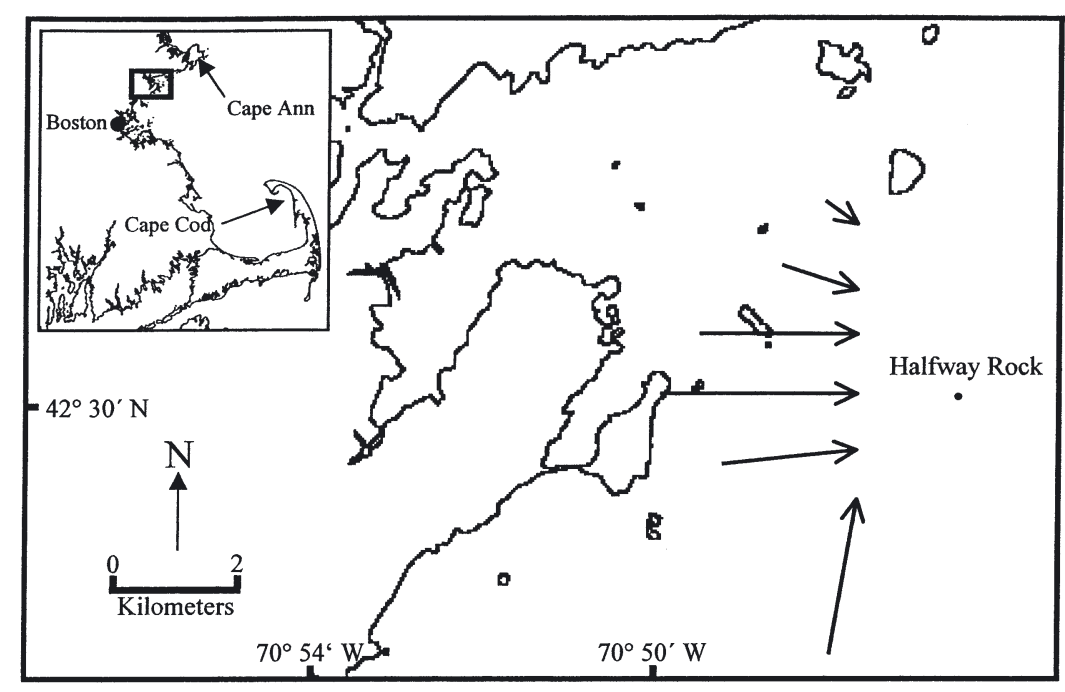

Fig. 1. Location of study site $(\bullet)$. Arrows indicate wind speed (proportional to arrow length) and direction on the days that water-flow measurements were taken. Wind speeds ranged from 2.5 to 15.1 knots 
densities, individual sea urchins Strongylocentrotus droebachiensis, seastars Asterias forbesi, and kelp Alaria esculenta were counted in each photograph. The percent cover of the blue mussel Mytilus edulis was quantified by identifying their presence under 200 randomly placed dots imposed onto the photographs by printing them on acetate sheets taped to the screen of a backlit slide projector.

Hydrodynamic site characteristics. The hydrodynamic characteristics of both sites were quantified in situ using a Sontek ${ }^{\circledR} 10 \mathrm{MHz}$ Acoustic Doppler Velocimeter $\left(\mathrm{ADV}^{\circledR}\right)$. Velocity measurements were taken at 5 to 6 depths, ranging from 1 to $12 \mathrm{~m}$. The instrument was weighted down with 2 lead weights (total weight $\approx 10 \mathrm{~kg}$ ) and placed securely on the sloping bedrock substratum. All flow records were recorded at $25 \mathrm{~Hz}$ for $5 \mathrm{~min}$ per depth approximately $4 \mathrm{~cm}$ above the substratum. Replicate measurements for both sites and each depth were taken between 2 and 30 October 1997. Since organisms must withstand the extremes an environment presents in order to persist, we used 99th percentile water velocities and accelerations to compare between sites and depths. We assumed that water flow was predominately parallel to the substratum. Due to the inclination and rugosity of the substratum, the flow probe likely was not always oriented perfectly in-line with the prevailing water flow. Thus, to correctly quantify total water velocity (U), the vector sum of the $x^{-}, y_{-}$, and $z$-axis velocities (relative to the probe) were combined. Total acceleration $\left(\mathrm{dU} \mathrm{dt}^{-1}\right)$ was calculated as the vector sum of each $x^{-}, y^{-}$, and $z$-axis acceleration $\left(\mathrm{dUx}_{\mathrm{dt}}{ }^{-1}, \mathrm{dU}_{y}\right.$ $\mathrm{dt}^{-1}$, and $\mathrm{dUz} \mathrm{dt}^{-1}$ ). Prior to all calculations, all data files were filtered to remove any extremely errant velocity readings. Data points which produced accelerations $>5.0 \mathrm{~m} \mathrm{~s}^{-2}$ over a $0.04 \mathrm{~s}$ time interval $(<0.8 \%$ of total $)$ were visually examined and replaced with an average velocity taken from data points before and after the data point in question. In addition, water velocities were measured throughout the transplant experiments (see below) to document similar conditions to those used to characterize the sites. Two replicate flow measurements at each site-depth combination (1 and $3 \mathrm{~m}$ ) were taken on 23 May 2002 using the ADV.

We also quantified maximum wave forces at our sites over a 2 wk time period that spanned 2 storm events. Maximum wave-force data were collected using 2 replicate maximum force dynamometers in situ (Bell \& Denny 1994). Two dynamometers were attached to eyebolts epoxied to the bedrock at each site-depth combination throughout the duration of the transplant experiments.

Since wave heights and therefore water velocities are often strongly correlated with wind speed and direction, wind data were obtained from the closest
NOAA weather buoy to examine how large-scale weather patterns and geographic orientation of the sites influence community dynamics. Each day, water flow measurements were taken, and average wind speed and direction data were examined from 08:00 to 16:00 h (daylight hours), which encompassed the times we collected all data. Wind direction was calculated as the average angle and the $99 \%$ confidence interval (Zar 1984). Wind data were obtained from the Isles of Shoals weather station (IOSN3; 42 $97^{\prime} \mathrm{N}, 70^{\circ} 62^{\prime} \mathrm{W}$ ), $53 \mathrm{~km}$ NNE from Halfway Rock (see www.ndbc.noaa. gov/station_history.phtml?\$station=iosn3); there were no data collected from the Boston buoy (18 km away) over this time period.

Attachment strengths. We quantified the maximum forces necessary to dislodge both sea urchins and seastars. Data were then compared to the calculated hydrodynamic forces (see next subsection) imposed on these organisms over the range of water velocities measured in situ.

Maximum attachment strengths of Strongylocentrotus droebachiensis and Asterias forbesi were measured in situ at both the exposed and protected sites. We haphazardly selected individuals on the open substratum (i.e. not in crevices or depressions), between 1 and $4 \mathrm{~m}$ depths. The procedure consisted of tapping individuals on their aboral surface to stimulate attachment of their tube feet. Next, a 4-tined metal harness was placed around the urchin test or between seastar arms and carefully tightened around the individual (see Witman 1987). A force gauge (Wagner Instruments, Force Dial ${ }^{\mathrm{TM}}$ ) was attached to the harness and then carefully pulled in a direction perpendicular $\left(90^{\circ}\right)$ to the substratum until the individual detached, and the maximum force was recorded to the nearest Newton $(\mathrm{N})$. The actual hydrodynamic forces imposed on the organisms were estimated at approximately 50 and $64^{\circ}$ from the substratum for urchins and seastars, respectively (angles calculated using the arctan of the lift divided by the drag forces). We assumed that there was minimal difference in attachment strengths between our measurements and those imposed by a force applied at 50 and $64^{\circ}$. The test diameter of sea urchins and the maximum arm length (center of aboral surface to tip of longest arm) of seastars were also measured using a plastic ruler to the nearest $0.5 \mathrm{~cm}$.

Hydrodynamic force calculations. Hydrodynamic forces were calculated for 3 size classes of each species over the range of water velocities measured in the field. These forces were then compared to the attachment strengths of the organisms to predict the probability of dislodgement as a function of water velocity. Probability of dislodgment, $p_{\mathrm{x}}$ equals the number of organisms (n) in size class $\mathrm{x}$ with attachment strengths $<$ the maximum total force $\left(F_{\mathrm{t}}\right)$ predicted from the flow 
data, divided by the total number of organisms ( $\left.n_{\text {total }}\right)$ within that size class (adjusted due to incomplete sampling; Gaines \& Denny 1993):

$$
p_{\mathrm{x}}=\frac{n_{<F_{\mathrm{t}}}}{n_{\text {total }}+1}
$$

We then back-calculated the velocities required to dislodge 25, 50 and $95 \%$ of the urchins and seastars (i.e. when $p_{\mathrm{x}}=0.25,0.50$, and 0.95).

The hydrodynamic forces imposed upon stationary organisms by moving fluids can be predicted by the speed and acceleration of the fluid, and the morphology of the organism using the Morison equation (Denny 1988). The total force $\left(F_{t}\right)$ acting on an organism can be defined as:

$$
F_{\mathrm{t}}=\sqrt{\left(F_{\text {inline }}\right)^{2}+F_{1}^{2}}
$$

where the inline force $\left(F_{\text {inline }}\right)$ is the summation of the $\operatorname{drag}\left(F_{\mathrm{d}}\right)$ and acceleration $\left(F_{\mathrm{a}}\right)$ forces, which are parallel to the fluid velocity, and the lift force $\left(F_{1}\right)$ imposed at an angle perpendicular to the fluid flow (Denny 1988). Calculations showed that forces imposed on urchins from acceleration were minimal (C.E.S. \& J.D.W. unpubl. data). For example, the force due to acceleration imposed on a large urchin at $10 \mathrm{~m} \mathrm{~s}^{-2}$ would be $1.1 \mathrm{~N}$. In addition, the probability of dislodgment of the congener Strongylocentrotus purpuratus is nearly independent of acceleration (Denny \& Gaylord 1996). Thus, forces due to acceleration were excluded.

Drag forces depend on fluid velocity $\left(U\right.$, in $\left.\mathrm{m} \mathrm{s}^{-1}\right)$ and the profile area of the organism $\left(A_{\mathrm{pr}}\right.$, in $\mathrm{m}^{2}$; defined as the area of a body projected onto a plane perpendicular to the flow direction):

$$
F_{\mathrm{d}}=0.5 \rho C_{\mathrm{d}} A_{\mathrm{pr}}|U| U
$$

where $C_{d}$ is the drag coefficient (dimensionless) specific to a given organism and $\rho$ is the density of seawater $\left(1024 \mathrm{~kg} \mathrm{~m}^{-3}\right)$.

The lift force, similar to the drag force, depends on the water velocity and an area measurement. However, this area is known as the planform area $\left(A_{\mathrm{pl}}\right.$, in $\mathrm{m}^{2}$, defined as area of a body projected on a plane perpendicular to the lift force):

$$
F_{1}=0.5 \rho C_{1} A_{\mathrm{pl}} U^{2}
$$

where $C_{\mathrm{l}}$ is the lift coefficient (dimensionless). More detailed treatments of lift, drag and acceleration are given in Denny et al. (1985), Vogel (1994), Denny (1995), and Denny \& Gaylord (1996).

By substituting the drag- (Eq. 3) and lift- (Eq. 4) force equations back into the Morison equation (Eq. 2), the total fluid force imposed on the organisms can be calculated using the appropriate values corresponding to each organism (i.e. $C_{\mathrm{d}}, C_{\mathrm{l}}, A_{\mathrm{pr}}, A_{\mathrm{pli}}$ Table 1). Since we assumed no forces due to acceleration, $F_{\text {inline }}$ equals $F_{\text {drag. }}$ Forces were calculated for 3 size classes: 20 to 35, 35 to 50 and 50 to $65 \mathrm{~mm}$ of test diameter for urchins, and 25 to 45,45 to 65 , and 65 to $90 \mathrm{~mm}$ of maximum arm length for seastars. These size classes corresponded to the range of sizes encountered while measuring attachment strengths of sea urchins and seastars in the field.

The morphometric parameters $\left(A_{\mathrm{pr}}, A_{\mathrm{pl}}\right)$ necessary to calculate the lift and drag forces were calculated using empirically derived regression equations of body size on the characteristic areas. The resulting regression equations were then used to back-calculate the appropriate areas for the largest individual in each size class (i.e. 35, 50, and $62 \mathrm{~mm}$ for urchins). These calculations provided the largest possible force (i.e. most conservative) to compare to the empirical attachment strengths.

The regression equations were derived by comparing test diameter or maximum arm length to areas $\left(A_{\mathrm{pl}}\right.$ and $A_{\mathrm{pr}}$ ) of 50 urchins and 50 seastars, respectively. Test diameters and maximum arm lengths were measured using vernier calipers (to nearest mm). Areas ( $A_{\mathrm{pl}}$ and $A_{\mathrm{pr}}$ ) of each individual were measured by analyzing digital photographs using Scion Image(C) software (Beta version 4.0.2). Digital photographs were taken of each individual (top and side views; $A_{\mathrm{pl}}$ and $A_{\text {pr, }}$ respectively). Photographs were opened in Scion Image $\odot$, organisms were outlined by hand, and areas were calculated by calibrating the pictures with a metric ruler within each picture. Regression analysis was performed on natural log-transformed data for both dependent and independent variables.

Values for the coefficients of drag and lift (Table 1) for the species used in this study were assumed to be similar to those reported for the sea urchin Strongylocentrotus purpuratus (Denny \& Gaylord 1996) and the seastar Asterina miniata (Denny 1995).

Transplant experiments. We tested the hypothesis that water flow, on calm days, produces sufficient force to dislodge sea urchins and seastars, using a common garden transplant technique, in May 2002. Sea urchins and seastars were tested separately using an identical design. Five $1 \mathrm{~m}^{2}$ clearings were created at both exposed and protected sites and at 2 depths within each site (1 and $3 \mathrm{~m}$ below mean low water; only 4 clearings were made at the shallow exposed site). Five urchins or seastars (45 to $65 \mathrm{~mm}$ test diameter or 60 to $100 \mathrm{~mm}$ arm length) were placed in each clearing at high tide. Experimental animals were collected from a site of intermediate exposure, approximately halfway between the exposed and protected sites from a depth of 2 to $3 \mathrm{~m}$. Potential confounding effects of different substratum types were eliminated by clearing all plots of macro-flora and fauna (except crustose coralline algae) using paint scrapers and wire brushes at least 
Table 1. Parameters used to calculate forces and the probability of dislodgment for each size class. Drag and lift coefficients are from the sea urchin Strongylocentrotus purpuratus (Denny \& Gaylord 1996) and the seastar Asterina miniata (Denny 1995). All other parameters are measured from the urchin $S$. droebachiensis and the seastar Asterias forbesi

\begin{tabular}{|c|c|c|c|c|c|}
\hline & $\operatorname{Drag}\left(C_{\mathrm{d}}\right)$ & Lift $\left(C_{\mathrm{l}}\right)$ & $\begin{array}{l}\text { Profile area } \\
\qquad\left(A_{\text {pri }} \mathrm{m}^{2}\right)\end{array}$ & $\begin{array}{l}\text { Planform area } \\
\qquad\left(A_{\mathrm{pl} ;} \mathrm{m}^{2}\right)\end{array}$ & $\begin{array}{c}\text { Probability of } \\
\text { dislodgment } \\
(\%)\end{array}$ \\
\hline S. droebachiensis & 1.00 & 0.55 & & & \\
\hline Small (35 mm) & & & 0.0007 & 0.0014 & 5.9 \\
\hline Medium (50 mm) & & & 0.0014 & 0.0028 & 3.4 \\
\hline Large $(62 \mathrm{~mm})$ & & & 0.0020 & 0.0042 & 2.2 \\
\hline A. forbesi & 0.44 & 0.14 & & & \\
\hline Small (45 mm) & & & 0.0004 & 0.0020 & 0.0 \\
\hline Medium (65 mm) & & & 0.0008 & 0.0043 & 0.0 \\
\hline Large (90 mm) & & & 0.0013 & 0.0085 & 0.0 \\
\hline
\end{tabular}

$24 \mathrm{~h}$ prior to the experiments. The cleared substratum was similar to a barrens habitat, where both species naturally occur. All other urchins and seastars were removed from the surrounding areas to aid in determining the fate of the experimental animals and to eliminate possible immigration into the clearings. All clearings were spaced $\geq 1 \mathrm{~m}$ from one another. Our response variable was the number of individuals that moved $>1 \mathrm{~m}$ from the original release point after $2 \mathrm{~h}$. Since all other urchins and seastars were cleared from the surrounding area, we could account for all the experimental animals. Data for the $2 \mathrm{~h}$ response were collected for 3 separate trials $(10,12$, and 17 May for sea urchins; 19, 20, and 23 May for seastars). Data were analyzed as a 3-way, mixed-model ANOVA (Trial: random; Site and Depth: fixed) using JMP $\left({ }^{\circledR}\right.$ statistical software Version 4.0.4) and declaring Trial, Trial $\times$ Site, Trial $\times$ Depth, and Trial $\times$ Site $\times$ Depth as random effects. Preliminary analysis showed no Trial or Trial-by-treatment interactions (all p-values $>0.08$ ) for either urchins or seastars, therefore data for the 3 trials were pooled. Thus, the final analyses were done as a 2-way ANOVA with fixed effects (Site and Depth).

\section{RESULTS}

\section{Community structure}

The subtidal community at the exposed site showed a clear pattern of urchin-dominated barrens in deeper water with an abrupt transition to a habitat dominated by fleshy macro-algae and mussels in shallow water (Fig. 2). Percent cover of the blue mussel Mytilus edulis dropped from $87.7 \%$ at $1.5 \mathrm{~m}$ to $0 \%$ at $4.5 \mathrm{~m}$ on the exposed side of the island in 1997. Similarly, the abundance of the kelp Alaria esculenta decreased from 45 ind. $0.25 \mathrm{~m}^{-2}$ to 0 over the same depth range. At the protected site, mussels and kelp were absent in the surveys at 1.5 and $3 \mathrm{~m}$ depths. The consumers of these species, namely urchins and seastars, showed the opposite pattern of distribution. The most striking difference in zonation between the exposed and protected sides of the island was that urchins and seastars were absent from 1.5 and $3 \mathrm{~m}$ depths at the exposed site, but they occurred in densities of 33 and 2.5 ind. $0.25 \mathrm{~m}^{-2}$ (urchins and seastars, respectively) at $1.5 \mathrm{~m}$ depth at the protected site. The densities of urchins and seastars were similar at depths $\geq 4.5 \mathrm{~m}$ at both exposed and protected sites.

Re-sampling the subtidal community 3 yr later indicated that a similar zonation pattern occurred in 2000 (Fig. 2). The same differences in subtidal zonation between exposed and protected sites were apparent; however, the percent cover of mussels was higher (51\% vs $0 \%$ at 1.5 and $3 \mathrm{~m}$ ) at the protected site in 2000 than in 1997, and kelp abundance was higher (38.5 vs 7.7 ind. $0.25 \mathrm{~m}^{-2}$ ) at the exposed site in 1997. The data indicated a large subtidal settlement of blue mussels in 2000, which occurs episodically in the Gulf of Maine (Witman et al. 2003).

\section{Hydrodynamic site characteristics}

Water movement at both sites was characterized by a mixture of turbulent and oscillatory flow in 3 planes (Fig. 3). The peak velocities were approximately 3 times greater at the exposed site than the protected site at $1.5 \mathrm{~m}$ depth on 13 October, when the wind speed was only 2.5 knots out of the northwest (Fig. 1).

Water velocities at both sites decreased with increasing depth, and there were higher water velocities at the exposed site at all depths (Fig. 4A). The greatest divergence between the exposed and protected sites occurred at the shallowest $(1.5 \mathrm{~m})$ depth. For example, the mean 99th percentile velocities were 2 times greater at the exposed site $\left(\bar{x}=1.00 \mathrm{~m} \mathrm{~s}^{-1}, \mathrm{SE}=0.18\right)$ than at the protected site $\left(\bar{x}=0.49 \mathrm{~cm} \mathrm{~s}^{-1}, \mathrm{SE}=0.18\right)$. 


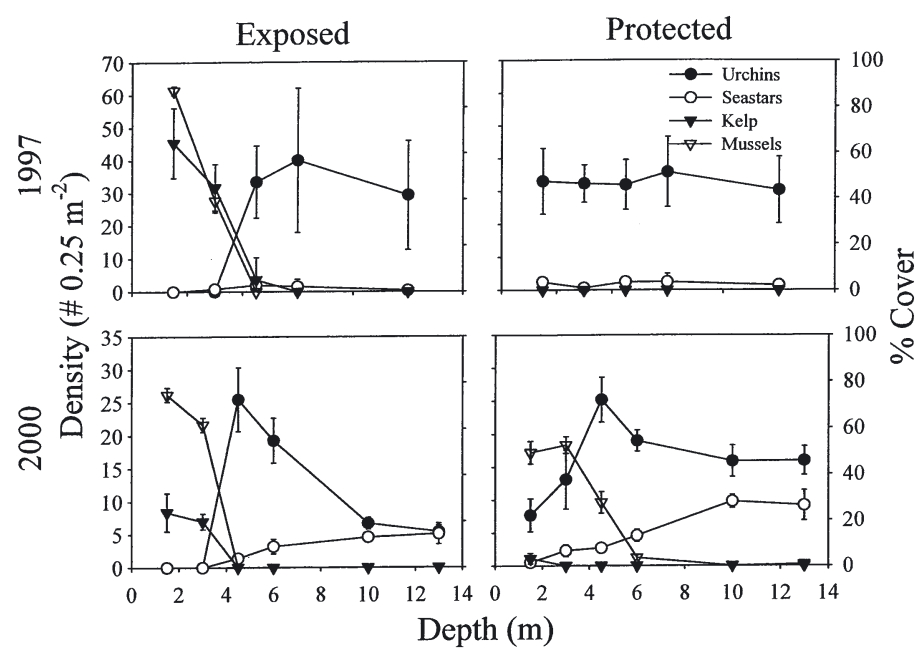

Fig. 2. Mean abundance $( \pm \mathrm{SE})$ of the dominant subtidal species from 1.5 to $13 \mathrm{~m}$ depth in October 1997 and November 2000 at the exposed and protected sites. Sea urchins Strongylocentrotus droebachiensis, seastars Asterias forbesi and kelp Alaria esculenta were measured as ind. $0.25 \mathrm{~m}^{-2}$. Mussels were quantified as \% cover. Mussels Mytilus edulis at the protected site were 0 at each depth in 1997, and thus overlap with the line for kelp abundance

The comparison of accelerations yielded a similar pattern to that of the velocity (Fig. 4B). Acceleration at both sites decreased with increasing depths. The mean acceleration differed mostly between the exposed and protected sites at $1.5 \mathrm{~m}\left(\bar{x}=6.74 \mathrm{~m} \mathrm{~s}^{-2}, \mathrm{SE}=0.39 ; \bar{x}=\right.$ $4.95 \mathrm{~m} \mathrm{~s}^{-2}, \mathrm{SE}=0.68$, respectively). The forces produced by these accelerations were calculated as $<0.55 \mathrm{~N}$ for large urchins.

The average wind speed for all days sampled was 9.7 \pm 2.1 knots and was predominately off-shore (Fig. 1). The mean daily wind speed did not exceed 15.1 knots, and on 2 days (13 and 14 October) it was below 5 knots. Off-shore winds (NW to SW) have a relatively short fetch compared to on-shore winds. These wind data support our observations of calm seas $(<0.5 \mathrm{~m}$ wave height) during the period of flow measurements.

\section{Attachment strengths}

Attachment strengths for sea urchins and seastars did not significantly differ between exposed and protected sites ( $t$-tests; all $p$-values for slopes and intercepts > $0.10)$. Accordingly, data were pooled from each site into common regression lines for each species. Both urchins and seastars exhibited a weak positive relationship between body size and the force required to remove them from the benthos. Sea urchin test-diameter significantly explained only $7 \%$ of the variation in the attachment strength (natural-log transformed; ln Force $=2.05+$ $0.95 \times \ln$ Test diameter, $\mathrm{p}<0.0007, \mathrm{r}^{2}=0.07, \mathrm{n}=168$ ). Similarly, arm length explained only $8 \%$ of the attachment strength of seastars (ln Force $=0.94+0.29 \times \ln$ Arm length, $\mathrm{p}=0.0004, \mathrm{r}^{2}=0.08, \mathrm{n}=149$ ). Fig. 5 shows the extent of variation in attachment strengths as a function of body size. Average $( \pm \mathrm{SE})$ attachment strengths were $23.4( \pm 2.0), 41.4( \pm 2.8)$, and $46.3( \pm 2.4)$ $\mathrm{N}$ for sea urchins and $23.4( \pm 2.0), 31.7( \pm 1.6)$, and 34.0 $( \pm 3.5) \mathrm{N}$ for seastars (small, medium, and large sizes, respectively). The attachment strengths for both species were highly variable, although on average urchins had greater attachment strength than seastars $\left(\bar{X}_{\text {urchins }}=\right.$ $42.4 \mathrm{~N}, \mathrm{SE}=1.8 ; \bar{x}_{\text {stars }}=30.8 \mathrm{~N}, \mathrm{SE}=1.4$ ).

\section{Hydrodynamic force calculations}

The regression equations needed to derive the characteristic areas $\left(A_{\mathrm{pl}}, A_{\mathrm{pr}}\right)$ showed strong relationships
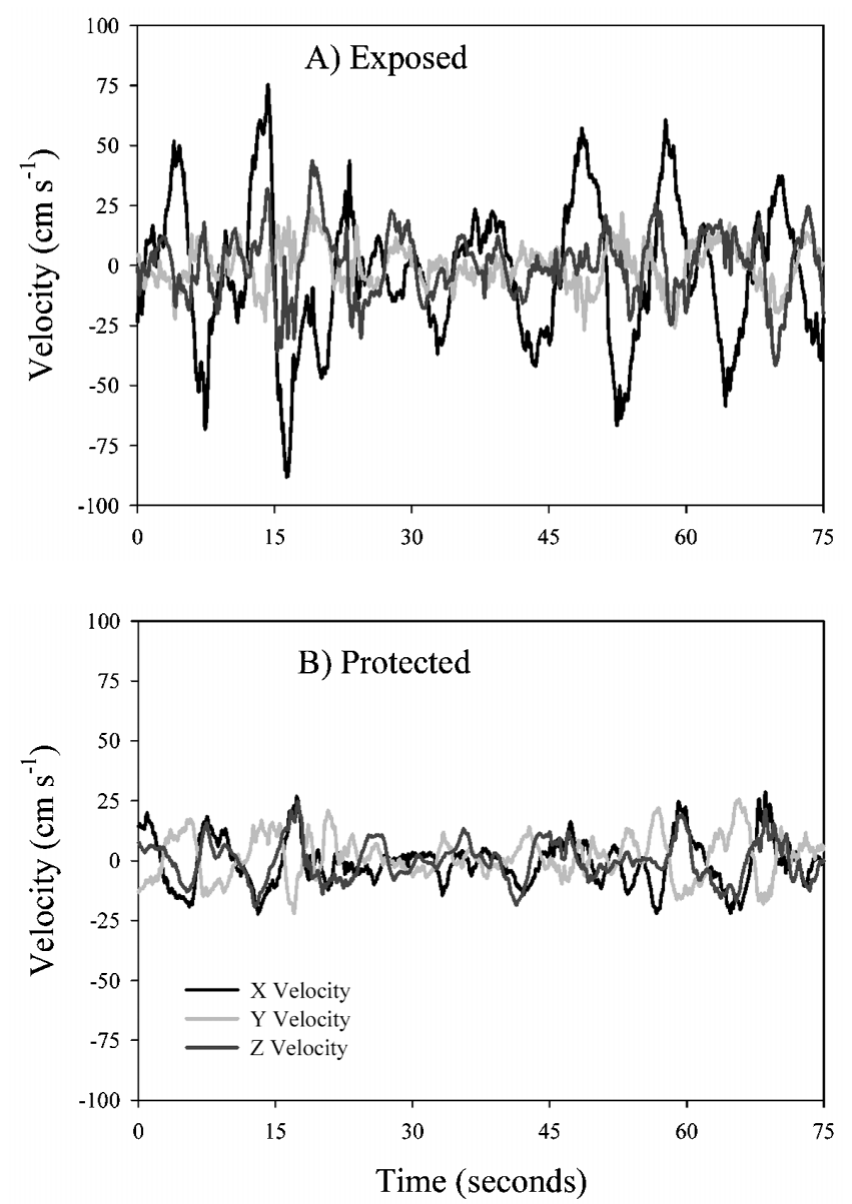

Fig. 3. Representative flow data at the exposed (A) and protected (B) sites of Halfway Rock. Flow measurements were taken at $1.5 \mathrm{~m}$ depth on 13 October 1997. Seventy-five seconds of a 5 min record are shown 

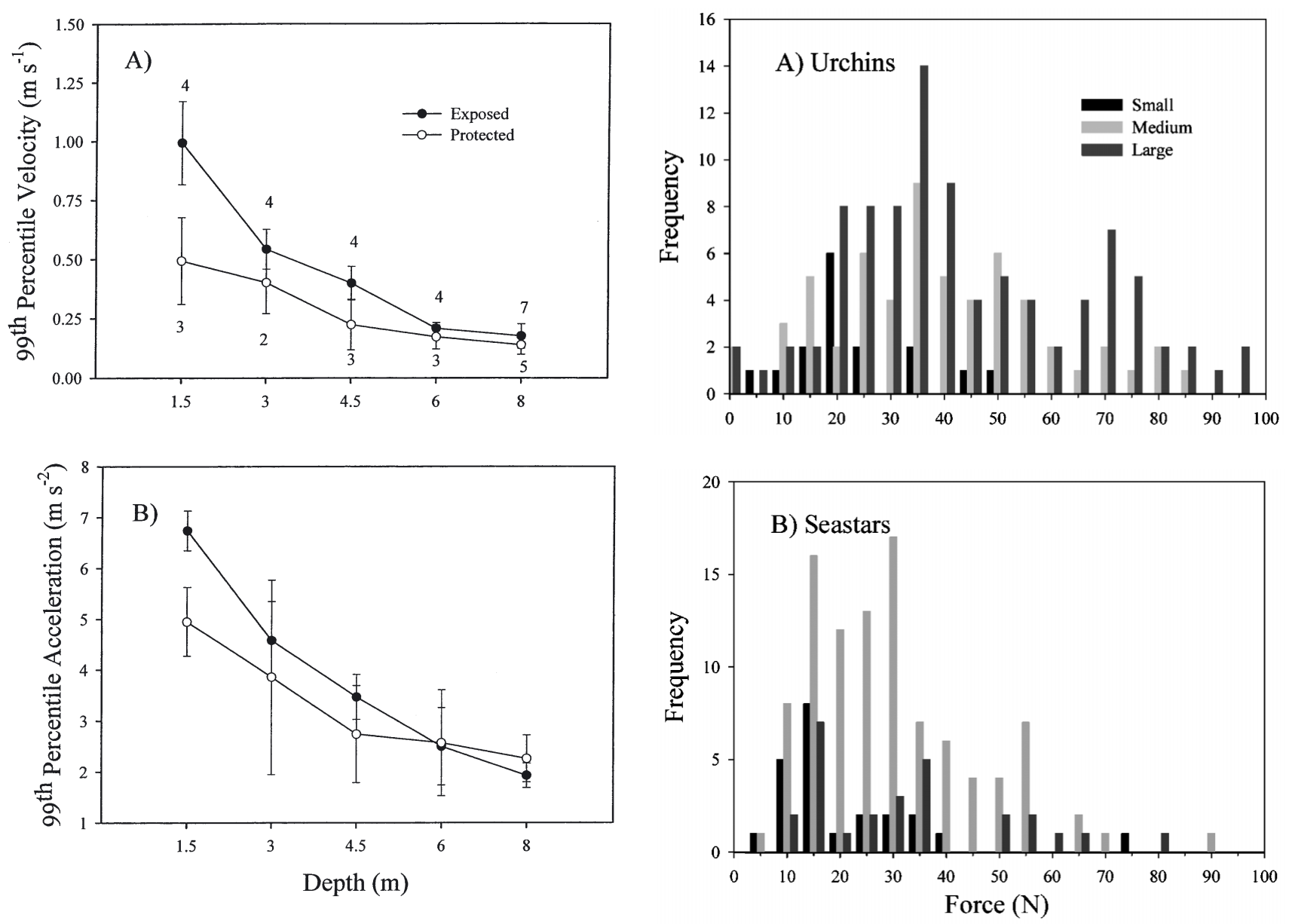

Fig. 4. Comparison of the 99th percentile $( \pm \mathrm{SE})$ velocities $(\mathrm{A})$ and accelerations (B) between exposed and protected sites. Sample sizes for each depth are shown above and below data points for exposed and protected sites, respectively. Samples size were the same for velocities and accelerations

between body size and area for both urchins and seastars (Fig. 6). Urchin test diameter explained $79 \%$ of the variation in profile area and $95 \%$ in planform area (ln $A_{\mathrm{pr}}=-0.997+1.871 \times \ln$ Test diameter, $\mathrm{p}<0.0001$, $\mathrm{r}^{2}=0.79, \mathrm{n}=50 ; \ln A_{\mathrm{pl}}=-0.099+1.930 \times \ln$ Test diameter, $\mathrm{p}<0.0001, \mathrm{r}^{2}=0.95, \mathrm{n}=50$ ). Seastar arm-length explained $27 \%$ of the profile area and $85 \%$ of the planform area $\left(\ln A_{\mathrm{pr}}=-3.074+1.496 \times \ln\right.$ Arm length, $\mathrm{p}<$ $0.0015, \mathrm{r}^{2}=0.27, \mathrm{n}=34 ; \ln A_{\mathrm{pl}}=0.193+2.060 \times \ln$ Arm length, $\mathrm{p}<0.0001, \mathrm{r}^{2}=0.85, \mathrm{n}=49$ ). From the regression equations we calculated the appropriate areas for the small, medium and large size classes used to calculate the total hydrodynamic forces imposed on the animals (Table 1).

Calculated drag and lift forces imposed on both species by the flow regime produced maximum total forces of 2.2, 3.9, and $5.4 \mathrm{~N}$ for sea urchins and 1.2, 1.9, and $2.9 \mathrm{~N}$ for seastars (small, medium and large size classes, respectively). When compared to the empiri-

Fig. 5. Strongylocentrotus droebachiensis and Asterias forbesi. Attachment strengths for small, medium, and large size classes (A: sea urchins, 20-35, 35-50, and 50-62 mm, $\mathrm{n}=$ 168; B: seastars, 25-45, 45-65, and 65-90 mm, $\mathrm{n}=149$ )

cally determined attachment strengths, these forces translated into probabilities of dislodgment of $<6.0 \%$ for urchins and $0 \%$ for seastars (Table 1 ). The predicted water velocities necessary to dislodge $95 \%$ of the large urchins and seastars were 7.5 and $9.9 \mathrm{~m} \mathrm{~s}^{-1}$, respectively (Fig. 7). These velocities were 6 to 10 times larger than any of the water velocities we measured on calm days, and similar to those recorded by maximum force dynamometers (see below).

\section{Transplant experiments}

The pooled data from the three $2 \mathrm{~h}$ trials revealed a significant effect of Site and a significant Site $\times$ Depth interaction on the number of individuals that moved more than $1 \mathrm{~m}$, for both urchins and seastars (Table 2). Contrary to our hypothesis, post-hoc Tukey tests showed that the least number of urchins and seastars 
moved out of the most physically stressful (shallow exposed) clearings than any other area ( $p<0.05$, Fig. 8). All of the animals that moved beyond the cleared release areas were located nearby. Thus, urchins and seastars were not dislodged from the most stressful environment. Instead, their movement was restricted compared to the other less hydrodynamically stressful treatments.

The water velocities during the transplant experiment, quantified using the ADV, showed similar magnitudes (i.e. small) to those used to characterize the sites. Averaged 99th percentile velocities on 23 May were $46.55 \pm 1.75$ and $33.60 \pm 11.60 \mathrm{~cm} \mathrm{~s}^{-1}$ (mean $\pm \mathrm{SE}$ ) for the shallow exposed and protected sites, respectively.

The dynamometers recorded forces over several storm events between the transplant trials. Results indicated that maximum water velocities at the exposed deep and protected shallow clearings were 8.8 and $8.3 \mathrm{~m} \mathrm{~s}^{-1}$, respectively, and $5 \mathrm{~m} \mathrm{~s}^{-1}$ at the protected deep clearings between 12 and 23 May. No data
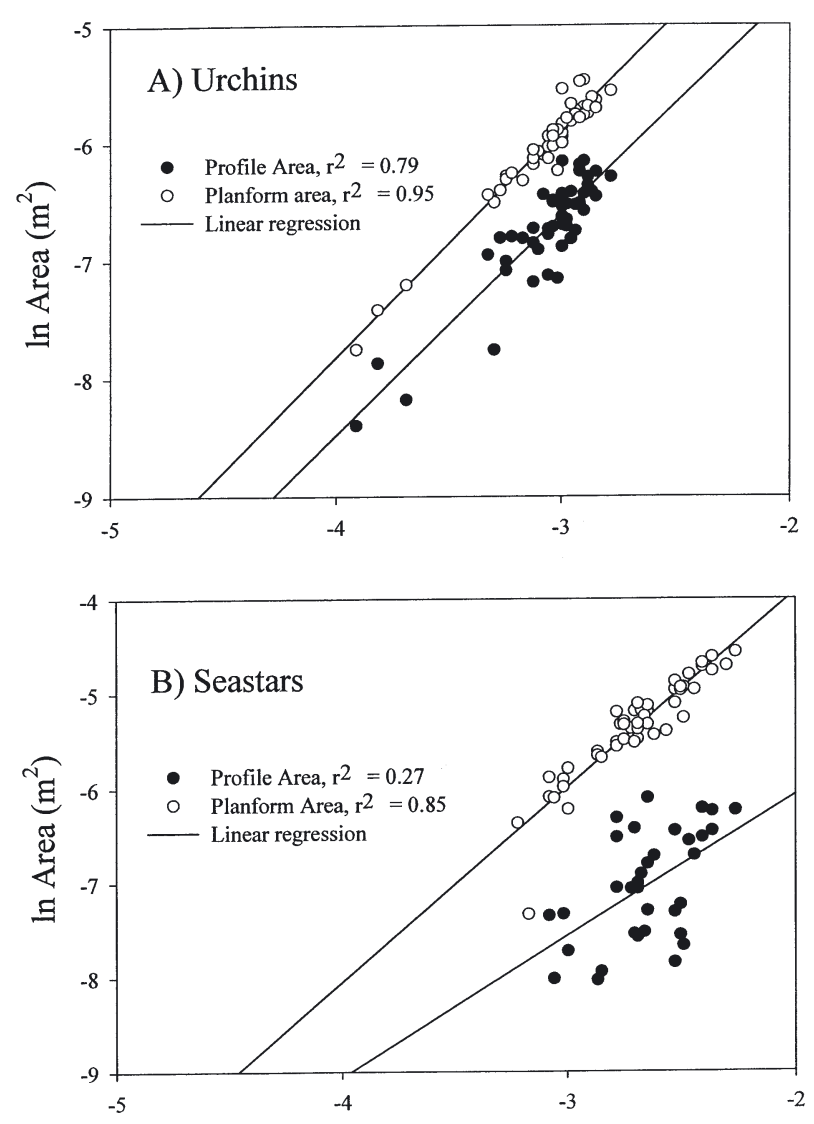

ln length (test diameter or arm length; $\mathrm{m}^{2}$ )

Fig. 6. Strongylocentrotus droebachiensis and Asterias forbesi. Relationship between body length and characteristic areas of urchins (A) and seastars (B). All p-values $<0.0015$ were recorded at the exposed shallow clearings because all the dynamometers were dislodged. We assume that the water velocities at the shallow exposed site exceeded those at the other sites.

\section{DISCUSSION}

The restriction of mobile consumer species to less physically stressful zones than their sessile prey is commonly observed in marine benthic communities (Paine 1966, Menge \& Lubchenco 1981, Witman 1987). Extremely large physical forces (Gaines \& Denny 1993) are capable of producing these zonation patterns by dislodging consumers in shallow habitats. Our data, however, suggest that chronic, low levels of water flow are sufficient to set up and maintain a persistent subti-
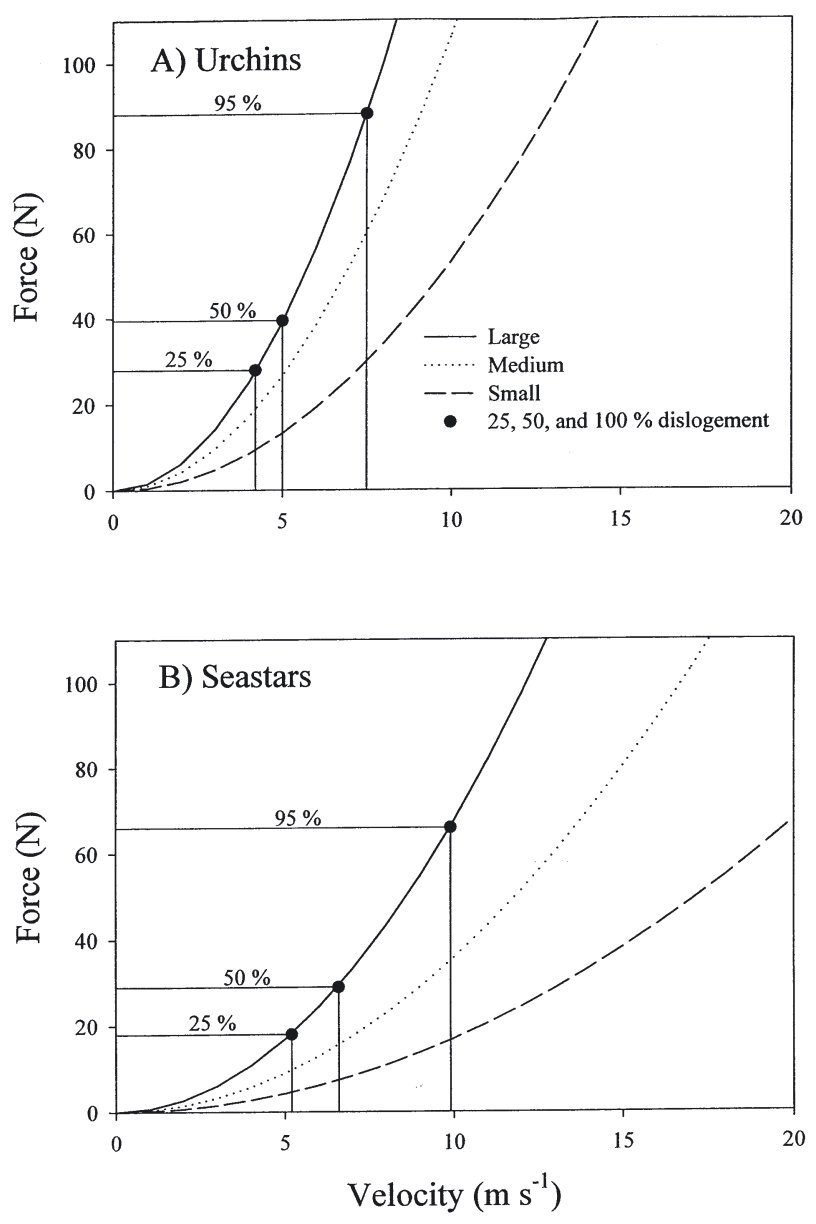

Fig. 7. Strongylocentrotus droebachiensis and Asterias forbesi. Projected velocities and their resultant forces imposed on small, medium, and large size classes of urchins (A) and seastars (B) using hydrodynamic force equations. Reference lines indicate forces and speeds at which 25,50 , and $95 \%$ of the large size classes would be dislodged. Even higher velocities would be required to remove similar percentages of medium and small animals 
Table 2. Strongylocentrotus droebachiensis and Asterias forbesi. Two-way ANOVA for the number of urchins and seastars that moved $>1 \mathrm{~m}$ after $2 \mathrm{~h}$ ( $\mathrm{n}=$ 15 , except $\mathrm{n}=12$ for shallow exposed treatment)

\begin{tabular}{|c|c|c|c|c|c|c|c|}
\hline \multirow{2}{*}{ Source } & \multicolumn{4}{|c|}{ Urchins } & \multirow{2}{*}{\multicolumn{2}{|c|}{ - Seastars }} & \multirow[b]{2}{*}{$\mathrm{p}$} \\
\hline & $\mathrm{df}$ & MS & $F$ & $\mathrm{p}$ & MS & & \\
\hline Site & 1 & 10.223 & 56.913 & $<0.001$ & 5.499 & 32.716 & $<0.001$ \\
\hline Depth & 1 & 0.679 & 3.781 & 0.0571 & 0.060 & 0.357 & 0.5526 \\
\hline Site $\times$ Depth & 1 & 2.672 & 14.877 & 0.0003 & 0.957 & 5.692 & 0.0207 \\
\hline Error & 53 & 0.180 & & & & & 0.100 \\
\hline
\end{tabular}

urchins and seastars from the benthos, since actual forces imposed on the organisms are more likely 50 to $64^{\circ}$ from the substratum. However, there are no data to test the relationship between dislodgment strength and the angle at which the force is applied for these species and, thus, we assumed they were independent.

In addition, meteorological data show that wind speed is less than 11 knots $25 \%$ of the time over a $1 \mathrm{yr}$

dal zonation pattern by limiting the ability of sea urchins and seastars to move and forage effectively. Comparisons between theoretical and empirical dislodgment strengths of both species, the return times of storm-generated water velocities, the movement rates of both species, and the results from our transplant experiment all confirm the importance of low-level water flow inhibiting the movement and foraging efficiency of sea urchins and seastars in the shallow subtidal.

Due to the detailed physical measurements needed to predict and experimentally test dislodgment for 2 species of consumers, we were not able to replicate the work at more than 2 sites. Thus, we cannot distinguish between a location effect (i.e. 2 locations on opposite sides of the island) and a wave-exposure effect. The generality of these results remains untested. However, we expect that further examination will show that these subtidal patterns and the processes behind them are general. For instance, the pattern of increased submergence of sea urchin distributions at exposed locations documented here also occurs at other areas within the Gulf of Maine (Witman 1987), in the Galápagos and Seychelles Islands (Witman \& Dayton 2001), and in Alaska (Konar \& Estes 2003). Therefore, it is possible that hydrodynamic limitations of behavior may be a pervasive mechanism underlying sea urchin distributions in other shallow subtidal systems.

Comparisons of theoretical and empirical dislodgment forces for both urchins and seastars suggest that only storm-generated waves would have sufficient force to dislodge these species from 1 to $4 \mathrm{~m}$ depth. Water velocities of 7.5 to $9.9 \mathrm{~m} \mathrm{~s}^{-1}$ are needed to dislodge $95 \%$ of the sea urchins and seastars (Fig. 7), whereas water velocities on relatively calm days predict only $6 \%$ dislodgment of sea urchins and $0 \%$ dislodgment of seastars. Our empirical dislodgment forces were measured at $90^{\circ}$ from the substratum. Dislodgment forces have been measured at 0 (Denny et al. 1985), 45 (Gallien 1986) and $90^{\circ}$ (Witman 1987, Bell \& Gosline 1997). Measuring dislodgment at $90^{\circ}$ may be an over-estimation of the force required to remove period. This suggests that there are long time intervals in which local wind-associated waves are minimal. Results from the dynamometers show that stormgenerated flow could produce a high probability of dislodgment. However, even if large wave forces exceed attachment strengths and remove urchins and seastars during storms, the return time of such storm conditions is only on the order of days to weeks in the Gulf of Maine (Witman 1985, Gaines \& Denny 1993). Thus, it is too long for dislodgment to solely explain the continued (1997 to 2000) scarcity of urchins and seastars from the shallow exposed site (Fig. 2), given the movement rates of sea urchins and seastars.

The movement rates and sensory systems of both species are sufficient to enable them to react to changes in water flow and allow them to move into the shallow zone between storms. Strongylocentrotus droebachiensis can move an average of $0.3 \mathrm{~m} \mathrm{~h}^{-1}$ in barren habitats at 6 to $10 \mathrm{~m}$ depth (Siddon et al. unpubl. data), and Asterias spp. have been shown to move at rates ranging from $1.09 \mathrm{~m} \mathrm{~d}^{-1}$ (Hulbert 1979) to $0.27 \mathrm{~m} \mathrm{~d}^{-1}$ (Altman \& Witman 1998). In addition, the results of our transplant experiment showed that sea urchins and seastars were capable of moving $>1 \mathrm{~m}$ (out of the clearings) within $2 \mathrm{~h}$ (Fig. 8). Since the linear distance between the 1 and $3 \mathrm{~m}$ depth stations was approximately 3 m (C. E. Siddon \& J. D. Witman unpubl. data), both species would be capable of repopulating the shallow sites in less than $6 \mathrm{~h}$. Moreover, if urchins were dislodged to a depth of $12 \mathrm{~m}$ (20 m linear distance), it would take as little as $40 \mathrm{~h}$ to repopulate the shallows.

The transplant experiment also indicated that both sea urchins and seastars in the shallow exposed clearings quickly attached and pulled in close to the substratum. Those individuals that were not allowed sufficient time to attach their tube feet to the bedrock were often dislodged as a wave passed over (C. E. Siddon \& J. D. Witman pers. obs.). However, in less than a minute they were able to react to the hydrodynamic conditions and fully attach, as required for the experimental design. This rapid reaction time is easily sufficient to sense and react to the changing water velocities of tides or storms. Moreover, we observed that 

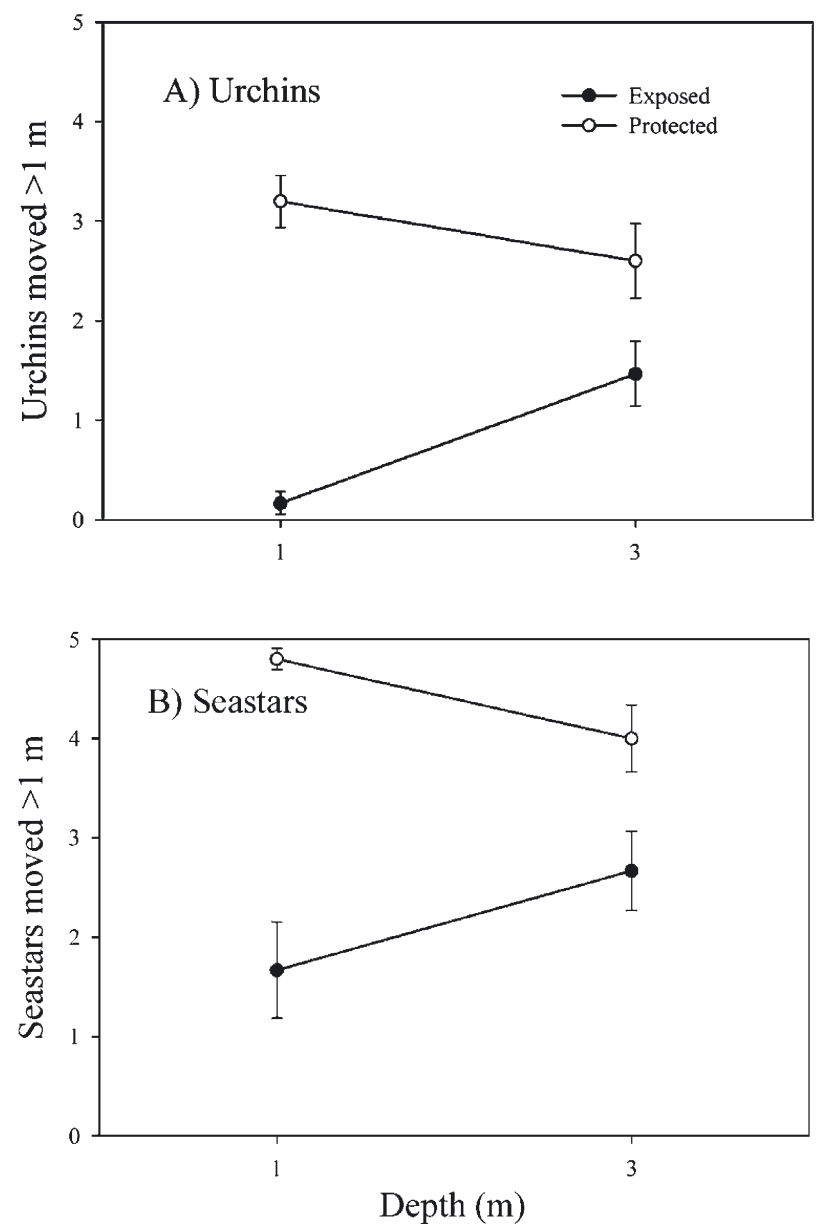

Fig. 8. Strongylocentrotus droebachiensis and Asterias forbesi. Number of individual urchins (A) and seastars (B) that moved $>1 \mathrm{~m}( \pm \mathrm{SE})$ at 1 and $3 \mathrm{~m}$ depths at the exposed and protected sites. $\mathrm{n}=5$ (except $\mathrm{n}=4$ in the shallow exposed treatment)

urchins and seastars were always found at the border between the barren and the mussel/kelp zones at both exposed and protected sites, even the day after a severe storm. For example, the maximum force dynamometers recorded forces that were consistent with water velocities $>8 \mathrm{~m} \mathrm{~s}^{-1}$ at $3 \mathrm{~m}$ depth over the entire period when the transplant experiments were conducted. These forces potentially exceeded the attachment strengths of most urchins and seastars. However, when transplant experiments were conducted the day after a storm (e.g. on 17 May), both species were found at the same depths as before the storms. This suggests that they were either able to withstand hydrodynamic forces during the storms, possibly by spine-locking in aggregations (urchins), or less likely, that they were dislodged and quickly re-populated the border. Regardless of the mechanism, these observations suggest that storm-generated hydrodynamic forces may not be the dominant factor determining the subtidal zonation of consumers in this system.

Although urchins and seastars were able to withstand significantly higher forces than those produced by non-storm conditions, and the return times for storms are relatively long compared to their movement rates, the distinct zonation pattern between exposed and protected sites still correlates strongly with the hydrodynamic regimes (Figs. 2 to 4). Our transplant experiments support the importance of hydrodynamic limitations on behavior, rather than on attachment strengths, in controlling the zonation pattern. Contrary to our predictions of dislodgment, most organisms remained in the most extreme environment (i.e. shallow [1.5 m] exposed) after $2 \mathrm{~h}$. In addition, the shallow exposed plots still contained more animals after 24 (seastars) and $48 \mathrm{~h}$ (sea urchins) than the protected plots (C. E. Siddon \& J. D. Witman unpubl. data). This indicates that sea urchins and seastars can persist in the shallow exposed habitat even though they don't typically occur there. In contrast, they attached and started moving freely about the benthos in the less physically extreme environments. Thus, we cannot reject our hypothesis that non-storm generated forces produced in the shallow subtidal are sufficient to dislodge urchins or seastars. However, these forces are sufficient to modify behavior from one of moving freely to one of reduced movement to remain attached to the substratum in high water-flow. This effectively limits the upper distribution of sea urchins and seastars.

Other studies corroborate our conclusion that relatively slow water (i.e. non-storm) velocities, with return times of seconds to minutes (Fig. 3), are sufficient to inhibit the distribution of benthic organisms by preventing their ability to move, and presumably to forage effectively. For example, laboratory studies of the sea urchin Strongylocentrotus nudus showed that water velocities of $0.7 \mathrm{~m} \mathrm{~s}^{-1}$ limited their mobility, while velocities of $<0.4 \mathrm{~cm} \mathrm{~s}^{-1}$ inhibited feeding (Kawamata 1998). Similarly, water velocities of $1 \mathrm{~m} \mathrm{~s}^{-1}$ removed nearly $100 \%$ of the gastropod Lacuna vincta from the stipes of Nereocystis leutkeana (Duggins et al. 2001). Although the study of L. vincta did not quantify the mechanism responsible for removing the snails, Martel (1991) showed that L. vincta can 'let go' of a kelp by lifting the anterior end of it's foot and producing a long mucus string, before reaching the limit of it's attachment strength. This behavior was commonly observed in the experiment performed by Duggins et al. (2001; C. E. Siddon pers. obs.). The flows used in all these experiments were similar in magnitude to the ones we recorded on calm days, and suggest that the distribution of mobile species can be inhibited through a change in behavior at water velocities significantly lower than those required to physically dislodge them. 
The interaction between water flow and predation is well known as being important in structuring communities (Leonard et al. 1998, Alfaro \& Carpenter 1999, Duggins et al. 2001, Robles et al. 2001). The model presented by Witman \& Dayton (2001) used the return time of a limiting stressor (e.g. water flow) and the mobility of the predator to predict their impact on the community. They predicted that as the return time increased, the impact of the consumer on the community would increase. Our results agree with their model, in that as the return time of the inhibitory flow increases from exposed to protected sides of the island, so does the impact of sea urchins and seastars on their sessile prey (Fig. 2). Their model also predicts that highly mobile consumer species should have a greater community impact than less mobile species, due both to higher metabolic rates and because of the fact that they can forage effectively even when return times of the stressor are short. Robles et al. (2001) showed that the highly mobile spiny lobster Panularis interruptus could forage effectively at water velocities that would inhibit sea urchin and seastar foraging. Although these studies support the Witman \& Dayton (2001) model, additional examples from a wide array of predators are necessary to test its generality.

In conclusion, our study highlights the importance of chronic, low-level forces in the structuring of shallow subtidal systems. Mobile organisms (especially of slow moving species) can be rendered ineffective at forces significantly lower than their physical or physiological limits. Thus, we must consider the influence of both chronic low-level forces and extreme forces (Gaines \& Denny 1993) to better understand how hydrodynamic forces act to structure communities.

Acknowledgements. We wish to thank D. McNaught, E. Calvert, A. Altieri, J. Ellis, J. Byrnes, and R. Miller for diving assistance in an inhospitable environment. R. Carpenter, M. Patterson, P. Ewanchuk, D. McNaught, and P. Petraitis provided helpful criticism and discussion. We are grateful to the Andrew Mellon Foundation and NSF Grant OCE - 959604 for their support of this research.

\section{LITERATURE CITED}

Alfaro AC, Carpenter RC (1999) Physical and biological processes influencing zonation patterns of a subtidal population of the marine snail, Astraea (Lithopoma) undosa Wood 1828. J Exp Mar Biol Ecol 240(2):259-283

Altman S, Witman JD (1998) A study of the movement and growth of the northern seastar, Asterias vulgaris, in the southern Gulf of Maine. BA thesis, Brown University, Providence, RI

Bell EC, Denny MW (1994) Quantifying wave exposure-a simple device for recording maximum velocity and results of its use at several field sites. J Exp Mar Biol Ecol 181: $9-29$
Bell EC, Gosline JM (1997) Strategies for life in flow: tenacity, morphometry, and probability of dislodgement of two Mytilus species. Mar Ecol Prog Ser 159:197-208

Blanchette CA (1997) Size and survival of intertidal plants in response to wave action: a case study with Fucus gardneri. Ecology 78:1563-1578

Boose ER, Foster DR, Fluet M (1994) Hurricane impacts to tropical and temperate forest landscapes. Ecol Monogr 64: 369-400

Briscoe CS, Sebens KP (1988) Omnivory in Strongylocentrotus droebachiensis (Müller) (Echinodermata: Echinoidea): predation on subtidal mussels. J Exp Mar Biol Ecol 115: $1-24$

Dayton PK (1971) Competition, disturbance, and community organization: the provision and subsequent utilization of space in a rocky intertidal community. Ecol Monogr 41: 351-389

Denny M (1988) Biology and mechanics of the wave-swept environment. Princeton University Press, Princeton, NJ

Denny M (1994) Extreme drag forces and the survival of wind-swept and water-swept organisms. J Exp Biol 194: 97-115

Denny M (1995) Predicting physical disturbance - mechanistic approaches to the study of survivorship on wave-swept shores. Ecol Monogr 65:371-418

Denny M (1999) Are there mechanical limits to size in waveswept organisms? J Exp Biol 202:3463-3467

Denny M, Gaylord B (1996) Why the urchin lost its spines: hydrodynamic forces and survivorship in three echinoids. J Exp Biol 199:717-729

Denny M, Daniel TL, Koehl MAR (1985) Mechanical limits to size in wave-swept organisms. Ecol Monogr 55:69-102

Duggins DO, Eckman JE, Siddon CE, Klinger T (2001) The interactive roles of mesograzers and flow on survival of kelps. Mar Ecol Prog Ser 223:143-155

Edmunds PJ, Witman JD (1991) effect of hurricane Hugo on the primary framework of a reef along the south shore of St. John, United States Virgin Islands. Mar Ecol Prog Ser 78:201-204

Ennos AR (1997) Wind as an ecological factor. Trends Ecol Evol 12:108-111

Gaines SD, Denny MW (1993) The largest, smallest, highest, lowest, longest, and shortest-extremes in ecology. Ecology 74:1677-1692

Gallien WB (1986) A comparison of hydrodynamic forces on two sympatric sea urchins: implications of morphology and habitat. MS thesis, University of Hawaii, Honolulu

Gaylord B, Blanchette CA, Denny MW (1994) Mechanical consequences of size in wave-swept algae. Ecol Monogr 64:287-313

Himmelman JH, Cardinal A, Bourget E (1983) Community development following removal of urchins, Strongylocentrotus droebachiensis, from the rocky subtidal zone of the St. Lawrence estuary, eastern Canada. Oecologia 59: 27-39

Hulbert AW (1979) The ecological role of Asterias vulgaris in three subtidal communities. Proc Eur Colloq Echinoderms, AA Balkema Press, Rotterdam, p 191-195

Kawamata S (1998) Effect of wave-induced oscillatory flow on grazing by a subtidal sea urchin Strongylocentrotus nudus (A-Agassiz). J Exp Mar Biol Ecology 224:31-48

Konar B, Estes JA (2003) The stability of boundary regions between kelp beds and deforested areas. Ecology 84: 174-185

Leonard GH, Levine JM, Schmidt PR, Bertness MD (1998) Flow-driven variation in intertidal community structure in a Maine estuary. Ecology 79:1395-1411 
Martel A, Chia FS (1991) Foot-raising behaviour and active participation during the initial phase of post-metamorphic drifting in the gastropod Lacuna spp. Mar Ecol Prog Ser $72: 247-254$

Menge BA (1979) Coexistence between the seastars Asterias vulgaris and Asterias forbesi in a heterogeneous environment: a non-equilibrium explanation. Oecologia 41: 245-272

Menge BA, Lubchenco J (1981) Community organization in temperate and tropical rocky intertidal habitats: prey refuges in relation to consumer pressure gradients. Ecol Monogr 51:429-450

Menge BA, Sutherland JP (1987) Community regulation: variation in disturbance, competition, and predation in relation to environmental stress and recruitment. Am Nat 130: $730-757$

Paine RT (1966) Food web complexity and species diversity. Am Nat 100:65-75

Paine RT, Levin SA (1981) Intertidal landscapes: disturbance and the dynamics of pattern. Ecol Monogr 51:145-178

Palumbi SR (1986) How body plans limit acclimation: responses of a demosponge to wave force. Ecology 67: 208-214

Robles CD, Alvarado MA, Desharnais RA (2001) The shifting balance of littoral predator-prey interaction in regimes of hydrodynamic stress. Oecologia 128:142-152

Scheibling RE, Hennigar AW, Balch T (1999) Destructive grazing, epiphytism, and disease: the dynamics of sea

Editorial responsibility: Ronald Karlson (Contributing Editor), Newark, Delaware, USA urchin - kelp interactions in Nova Scotia. Can J Fish Aquat Sci 56:2300-2314

Sousa WP (2001) Natural distubance and the dynamics of marine benthic communities. In: Bertness MD, Gaines SD, Hay ME (eds) Marine community ecology. Sinauer Associates, Sunderland, MA, p 85-130

Trussell GC (1997a) Phenotypic plasticity in the foot size of an intertidal snail. Ecology 78:1033-1048

Trussell GC (1997b) Phenotypic selection in an intertidal snail: effects of a catastrophic storm. Mar Ecol Prog Ser 151:73-79

Vogel S (1994) Life in moving fluids: the physical biology of fluid flow. Princeton University Press, Princeton, NJ

Witman JD (1985) Refuges, biological disturbance, and rocky subtidal community structure in New England. Ecol Monogr 55:421-445

Witman JD (1987) Subtidal coexistence: storms, grazing, mutualism and zonation of kelps and mussels. Ecol Monogr 57:167-187

Witman JD, Dayton PK (2001) Rocky subtidal communities. In: Bertness MD, Gaines SD, Hay M (eds) Marine community ecology. Sinauer Associates, Sunderland, MA, p 339-366

Witman JD, Genovese SJ, Bruno JF, McLaughlin JW, Pavlin BI (2003) Massive prey recruitment and the control of rocky subtidal communities on large spatial scales. Ecol Monogr 73:441-462

Zar JH (1984) Biostatistical analysis, Vol. Prentice-Hall, Englewood Cliffs, NJ

Submitted: December 2, 2002; Accepted: July 23, 2003

Proofs received from author(s): October 13, 2003 